\title{
BMJ
}

\section{Improving cardiovascular health at population level: 39 community cluster randomised trial of Cardiovascular Health Awareness Program (CHAP)}

\author{
Janusz Kaczorowski, professor, ${ }^{1,2,3}$ Larry W Chambers, president and chief scientist, ${ }^{4}$ Lisa Dolovich, associate \\ professor, ${ }^{2,5,6}$ J Michael Paterson, scientist,, Tina Karwalajtys, assistant professor, ${ }^{2}$ Tracy Gierman, director, ${ }^{8}$ \\ Barbara Farrell, scientist, ${ }^{4,9}$ Beatrice McDonough, public health nurse, ${ }^{10}$ Lehana Thabane, associate \\ professor, ${ }^{5}$ Karen Tu, scientist, ${ }^{7}$ Brandon Zagorski, analyst, ${ }^{7}$ Ron Goeree, associate professor, ${ }^{5}$ Cheryl A Levitt, \\ professor, ${ }^{2}$ William Hogg, professor, ${ }^{4,9,11}$ Stephanie Laryea, research assistant, ${ }^{2}$ Megan Ann Carter, research \\ associate, ${ }^{11}$ Dana Cross, acting director, ${ }^{8}$ Rolf I Sabaldt, associate clinical professor ${ }^{6}$
}

\begin{abstract}
'Department of Family Practice, University of British Columbia, 320-5950 University Boulevard, Vancouver, BC, Canada V6T $1 Z 3$ ${ }^{2}$ Department of Family Medicine, McMaster University, Hamilton, ON, Canada

${ }^{3}$ Child \& Family Research Institute, Vancouver

${ }^{4}$ Institut de recherche ÉlisabethBruyère Research Institute,

Bruyère Continuing Care and

University of Ottawa, Ottawa, ON,

Canada

${ }^{5}$ Department of Clinical

Epidemiology and Biostatistics, McMaster University, Hamilton

${ }^{6}$ Department of Medicine, McMaster University, Hamilton

${ }^{7}$ Institute for Clinical Evaluative Sciences, Toronto, ON, Canada

${ }^{8}$ Academic Health Council, University of Ottawa, Ottawa

${ }^{9}$ Department of Family Medicine, University of Ottawa

${ }^{10}$ Public Health Services, City of Hamilton, Hamilton

${ }^{11}$ Institute of Population Health, University of Ottawa
\end{abstract}

Correspondence to:JKaczorowski Janusz.kaczorowski@familymed. ubc.ca

Cite this as: $B M J$ 2011;342:d442 doi:10.1136/bmj.d442

\section{ABSTRACT}

Objective To evaluate the effectiveness of the community based Cardiovascular Health Awareness Program (CHAP) on morbidity from cardiovascular disease.

Design Community cluster randomised trial.

Setting 39 mid-sized communities in Ontario, Canada, stratified by location and population size.

Participants Community dwelling residents aged 65 years or over, family physicians, pharmacists, volunteers, community nurses, and local lead organisations. Intervention Communities were randomised to receive CHAP $(n=20)$ or no intervention ( $n=19)$. In CHAP communities, residents aged 65 or over were invited to attend volunteer run cardiovascular risk assessment and education sessions held in community based pharmacies over a 10 week period; automated blood pressure readings and self reported risk factor data were collected and shared with participants and their family physicians and pharmacists.

Main outcome measure Composite of hospital admissions for acute myocardial infarction, stroke, and congestive heart failure among all community residents aged 65 and over in the year before compared with the year after implementation of CHAP.

Results All 20 intervention communities successfully implemented CHAP. A total of 1265 three hour long sessions were held in 129/145 (89\%) pharmacies during the 10 week programme. 15889 unique participants had a total of 27358 cardiovascular assessments with the assistance of 577 peer volunteers. After adjustment for hospital admission rates in the year before the intervention, CHAP was associated with a $9 \%$ relative reduction in the composite end point (rate ratio $0.91,95 \%$ confidence interval 0.86 to $0.97 ; \mathrm{P}=0.002$ ) or 3.02 fewer annual hospital admissions for cardiovascular disease per 1000 people aged 65 and over. Statistically significant reductions favouring the intervention communities were seen in hospital admissions for acute myocardial infarction (rate ratio $0.87,0.79$ to 0.97 ;
$\mathrm{P}=0.008)$ and congestive heart failure $(0.90,0.81$ to 0.99 ; $\mathrm{P}=0.029)$ but not for stroke $(0.99,0.88$ to $1.12 ; \mathrm{P}=0.89)$. Conclusions A collaborative, multi-pronged, community based health promotion and prevention programme targeted at older adults can reduce cardiovascular morbidity at the population level.

Trial registration Current controlled trials ISRCTN50550004.

\section{INTRODUCTION}

In 2002 the World Health Organization identified high blood pressure as the leading risk factor for death, forecasting an epidemic of hypertension and identifying community programmes to prevent cardiovascular disease as a priority. ${ }^{1}$ Worldwide, $30 \%$ of all deaths are due to cardiovascular disease, and more than 54\% of deaths from stroke, $47 \%$ of those from ischaemic heart disease, and 14\% of all deaths are attributable to high blood pressure. ${ }^{23}$ Effective population based strategies for health promotion and disease prevention, both for people with established cardiovascular disease and for those at risk of developing it, are seen as critical to countering widespread and growing epidemics of obesity, hypertension, diabetes, heart disease, and stroke. ${ }^{4-6}$ Both the incidence and the prevalence of hypertension increase with age, and the lifetime residual risk of developing hypertension for a middle aged person with normal blood pressure is $90 \%{ }^{7}$

A recent review of community programmes for prevention of cardiovascular disease included $36 \mathrm{commu}-$ nity programmes that took place between 1970 and 2008 and concluded that although generally favourable changes in overall cardiovascular risk have been shown, considerable uncertainties about their effectiveness remain. ${ }^{8}$ The review further concluded that studies of programmes better adapted to current circumstances need to be implemented and rigorously evaluated before widespread implementation of such programmes can be recommended. Specific 
Essential elements of CHAP*

\section{Scope of programme: community-wide orientation}

- Community-wide orientation with a view to reaching all people in the community who are part of the broad "target audience" (residents aged 65 years or over)

- Cardiovascular risk assessment sessions offered free of charge

2. "Closing the loop": linkage to appropriate healthcare providers

- Family physicians, nurse practitioners, and pharmacists involved in referral/invitation to the programme and receiving feedback of patients' results

3. Accessible location/setting and enhanced continuity of care

- Regular weekly session held in community pharmacies (with appropriate healthcare professional present)

- Continuity of care (integrated healthcare) enhanced through explicit links between pharmacists and family physicians

4. Blood pressure measurement device and accurate measurement of blood pressure

- Use of a validated and accurate blood pressure measuring device (such as the BpTRU)

- Volunteers trained to measure blood pressure accurately

5. Referral for follow-up

- Blood pressure and chronic disease risk profile results used according to CHAP protocol to ensure that participants in CHAP pharmacy sessions are linked to appropriate health providers and resources

6. Global cardiovascular risk factor assessment and education

- Maintaining "global" risk factor assessment

- Aiming to increase awareness of modifiable risk factors for chronic disease, including cardiovascular disease and stroke

- Availability of resources and linkage to other local and provincial/national sources of information/programmes for modifiable risk factors

7. Feedback of results

- Transfer of all CHAP pharmacy sessions' results to primary healthcare provider(s), with participants' consent:

- For participants at high risk with CHAP protocol

- For all participants with CHAP summarised participants' results report form

- Comparative feedback to family physicians

\section{Evaluation}

- Process evaluation data collected for the purpose of ongoing evaluation and quality improvement:

- Success of different advertising/invitation strategies

- Attendance, consent, completed assessments

- Nurse assessments, pharmacist consults, fax/call to family physician the same day

- Feedback to family physicians, pharmacists, and participants

*See CHAP Implementation Guide (www.CHAPprogram.ca) for more information

methodological concerns about studies of programmes implemented in the past included the selection of appropriate control groups and the mode of collection of outcome data.

As a large fraction of cardiovascular disease is attributable to modifiable factors, finding an effective combination of approaches to improve awareness and prevention of risk factors is a high priority. We postulated that a locally delivered but standardised and centrally supported programme of cardiovascular health promotion and disease prevention targeting older adults could lead to improved management of cardiovascular risk factors and thus reduce morbidity at the population level.

\section{METHODS}

Study area and population

Ontario is Canada's most populous province, with approximately 13 million residents. We identified all municipalities in Ontario with a population of 10000 to 60000 , according to the 2001 Canadian census $(\mathrm{n}=41)$. We considered communities of this size to be optimal trial sites in terms of both standardised implementation and evaluation. We excluded two communities where the intervention was pilot tested..$^{9}$ The remaining 39 communities had a total population of 973246 in 2005, including 140642 people aged 65 years or over.

\section{Study design}

This study was a two arm cluster randomised controlled trial. A more detailed description of the study design, ${ }^{10}$ development of the Cardiovascular Health Awareness Program (CHAP), ${ }^{911} 12$ and CHAP's implementation have been published previously. ${ }^{13}$ In brief, we stratified the 39 eligible communities, geographically defined according to municipal boundaries, by population size (three strata) and geographical location (four strata). An independent expert in cluster randomised trials then used a random number generator to randomly allocate communities in each stratum to receive either CHAP $(n=20)$ or no intervention $(n=19)$. In both arms, residents received the usual health promotion and healthcare services available to all Ontarians under its publicly financed universal health insurance programme.

Although participants were informed that CHAP was being evaluated, we did not publicise the fact that evaluation was by a community randomised trial. To understand potential co-intervention and contamination, we identified public health units and other agencies in all study communities and contacted them in the year after the intervention to determine whether important cardiovascular health initiatives occurred during the study period.

\section{CHAP intervention}

The CHAP intervention was standardised and consisted of 10 weeks of three hour weekday blood pressure and cardiovascular risk factor assessment and educational sessions held concurrently in all 20 intervention communities during the autumn of 2006. The box lists the essential elements of CHAP. Local agencies recruited and trained volunteer peer health educators to help participants measure their blood pressure by using a validated, automated instrument (BpTRU, VSM MedTech, 2004). Blood pressure readings and other information on cardiovascular risk factors were recorded and, with participants' consent, sent to their family physician and usual pharmacist. CHAP volunteers supported self management by providing participants with their risk profile, risk specific educational materials, and information about availability of and 
Eligible Ontario communities

(population between 10000 and $60000 ; \geq 5$ family physicians; $\geq 2$ pharmacies) $(n=39)$

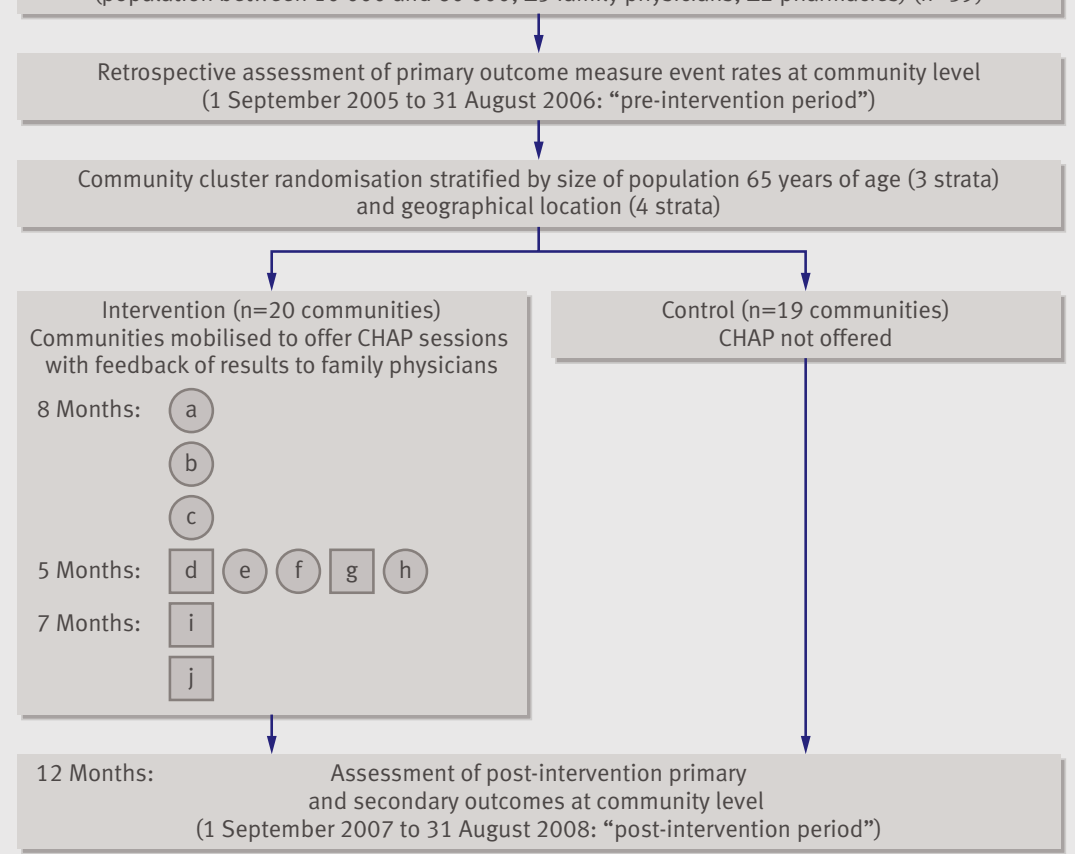

January to August 2006

Request for proposals for funding to deliver CHAP; local lead organisations chosen and local CHAP coordinators hired

Mobilisation activities by local lead organisation, including documentation of local capacities (such as stakeholders, programmes, and agencies), review and collection of ( identification of physician opinion leader and pharmacist champion, development of action plan to implement CHAP

Implementation activities led by the local CHAP coordinator with support from local lead organisations, including hiring community health nurse, recruiting family physicians and pharmacies, recruiting and training volunteer peer health educators, implementing invitation methods, and developing CHAP session schedules

September to November 2006

Participants assisted by volunteer peer health educators to complete the cardiovascular disease and stroke risk profile

Participants assisted by volunteer peer health educators to measure their blood pressure (BP) with BpTRU automated device and record result

On-call nurse called to reassess participants identified as being at high risk (systolic BP 180 or diastolic BP $110 \mathrm{~mm} \mathrm{Hg}$ ); family physician contacted and provided with session results by fax same day

g Participants provided with targeted educational resources by volunteer peer health educators on basis of risk profile responses

Copy of completed risk profile given to each participant and faxed to database

January 2007

Pharmacy session results for 10 week programme sent to participants' family physicians in form of reports rank ordering their patients by systolic BP (from highest to lowest) and diagnostic/treatment status

May to August 2007

Aggregate level comparative feedback along with individual patient data sent to family physicians showing BP control of patients from their practice who participated in CHAP compared with patients of other family physicians in their own community and across all 20 intervention communities

Profile of CHAP trial, including main components of intervention. CHAP=Cardiovascular Health Awareness Program access to local community resources. A community health nurse ensured immediate follow-up of participants identified as being at high risk on the basis of their systolic blood pressure, and an on-site pharmacist was available for drug related consultations.

We used "fax to database" technology to compile results from all sessions and forwarded them to family physicians at the end of the 10 week programme. Reports rank ordered their patients by their most recent systolic blood pressure within diagnostic/treatment groups (potentially new cases of hypertension and potentially under-treated/non-adherent patients) and, to reflect different blood pressure targets for patients with diabetes, self reported diabetes status. Six months after the end of sessions, family physicians received a copy of this report again, along with feedback showing the percentage of their patients with and without diabetes who reached systolic blood pressure target levels compared with those of other family physicians in their own community and of family physicians in all intervention communities combined.

\section{CHAP implementation}

We invited organisations with an interest in health promotion and experience in working with volunteers or volunteer run programmes, through a request for proposals, to implement CHAP as the local lead organisations in each community. The successful organisations represented a spectrum of community agencies, from hospitals and seniors' centres to primary care and community support organisations. Each received between \$C20 000 (£13 000; €15000) and \$C40 000 to support implementation of CHAP.

We encouraged the local lead organisations and their coordinators to use opinion leaders and peers to gain the support and participation of family physicians and pharmacies. ${ }^{14}$ We invited all family physicians with an office address in an intervention community to participate. Participation involved sending personalised invitations, hand distributing referral letters, and encouraging their patients aged 65 and older to attend the CHAP sessions. When required, CHAP support staff produced and mailed invitation letters on behalf of participating physicians. We invited all community based pharmacies located in the intervention communities to participate. Participation involved providing space and pharmacist support during CHAP sessions and encouraging clients to participate.

The local lead organisations used several strategies to recruit volunteer peer health educators. These strategies included using the local lead organisation's existing volunteer base, advertising in the local media, and giving presentations at local seniors' clubs. The volunteers were trained according to a standardised curriculum developed by a public health nurse and delivered by nurses working in each intervention community.

Anyone visiting a participating pharmacy could take part in a CHAP session. However, people aged 65 years or over were explicitly targeted. In addition to invitations and referrals from participating family 
Table 1|Baseline characteristics of CHAP trial communities (on 1 September 2006). Values are means (SD)

\begin{tabular}{|c|c|c|}
\hline & $\begin{array}{l}\text { Control communities } \\
\qquad(n=19)\end{array}$ & $\begin{array}{l}\text { Intervention communities } \\
\qquad(\mathrm{n}=20)\end{array}$ \\
\hline \multicolumn{3}{|l|}{ Demographic characteristics } \\
\hline No of residents aged $\geq 65$ years & 3829.89 (2176.44) & 3393.70 (1831.59) \\
\hline Age (years) & $74.79(0.43)$ & $74.82(0.62)$ \\
\hline Male sex (\%) & $42.65(1.19)$ & $42.92(2.16)$ \\
\hline Rurality index ${ }^{20}$ & $28.96(13.60)$ & $31.63(14.09)$ \\
\hline Low income status (\%)* & $16.95(8.55)$ & $18.57(11.33)$ \\
\hline \multicolumn{3}{|l|}{ Morbidity } \\
\hline No of prescription drugs in previous year & $7.25(0.49)$ & $6.98(0.54)$ \\
\hline No of comorbidity groups in previous 2 years ${ }^{21}$ & $7.31(0.30)$ & $7.17(0.50)$ \\
\hline Charlson comorbidity index in previous 2 years ${ }^{22}$ & $0.57(0.09)$ & $0.58(0.11)$ \\
\hline Diabetes $(\%)^{23}$ & $22.16(2.34)$ & $21.20(2.79)$ \\
\hline History of congestive heart failure $(\%)^{24}$ & $12.19(1.91)$ & $12.45(2.34)$ \\
\hline \multicolumn{3}{|l|}{ Mortality } \\
\hline Death rate per 100 in previous year & $3.45(0.40)$ & $3.55(0.57)$ \\
\hline
\end{tabular}

* Member of lowest fifth of neighbourhood income in 2006 Canadian census.

physicians, pharmacies, or the local lead organisation, we advertised CHAP sessions by using flyers, posters, and paid and unpaid advertisements in the local media.

We coordinated CHAP centrally throughout the study. This took the form of weekly teleconferences with the central CHAP team, local coordinators, monthly newsletters, an interactive web forum, and site visits to assist with promotion and implementation of CHAP. Other centralised services included preparation of community profiles from secondary data sources, including sociodemographic characteristics, prevalence of cardiovascular risk factors, and lists of family physicians, pharmacies, and local cardiovascular disease resources; cardiovascular disease risk assessment forms; promotional posters and press release templates; the implementation guide (available at www.CHAPprogram.ca) comprising week by week guidance and materials for recruitment, training, and retention of volunteers, strategies for recruiting family physicians and pharmacists, and communications; and electronic data management services. Two regional coordinators provided support to the local CHAP coordinators and their local lead organisations.

\section{Evaluation}

Evaluation of the programme was independent of its implementation and relied on routinely collected, population based administrative health data housed at the Institute for Clinical Evaluative Sciences (www. ices.on.ca). Data sources included hospital discharge abstracts from the Canadian Institute for Health Information, physician service claims from the Ontario Health Insurance Program, and prescription drug claims from the Ontario Drug Benefit Program. These datasets have been used extensively in health services research, and the core data elements have high levels of completeness and validity.

The primary outcome measure was the relative change in the mean annual rate of hospital admissions with a "most responsible" (primary) discharge diagnosis of acute myocardial infarction, congestive heart failure, or stroke (composite end point) among community dwelling residents aged 65 years and over in the year before compared with the year after implementation of CHAP. Because of the short follow-up period, we elected to use a composite end point to increase the event rates and thus the statistical power. The study admissions were coded in the Canadian Institute for Health Information's discharge abstract database with ICD-10-CA (international classification of diseases, 10th revision, Canadian enhancement). The diagnoses comprising the primary outcome measure were validated and have high positive predictive value. ${ }^{15-18}$ Because the data are population based, hospital admissions could be attributed to patients' place of residence regardless of where they occurred. Secondary outcome measures included mortality during the above hospital admissions, all cause mortality, and newly prescribed antihypertensive drug treatment. $^{19}$

\section{Statistical analysis}

The sample size was pre-determined, as only $39 \mathrm{com}$ munities in Ontario met our eligibility criteria. We used rates of hospital admission for acute myocardial infarction, congestive heart failure, and stroke in these 39 communities and the 2001 census population estimates for people aged 65 years and over for power calculations. In 2001, a total of 11486 such hospital admissions occurred, with 148589 person years of observations, giving an overall admission rate of 77.3 per 1000 person years. The standard deviation of the observed admission rates was 17.9. With the assumption that the mean hospital admission rate in control communities remained constant, 19 communities per arm allowed detection of a $21 \%$ or greater reduction in the mean annual rate of hospital admission with $80 \%$ power (using a two tailed test at the $\alpha=0.05$ level of significance).

We did the primary analysis according to intention to treat; because treatment allocation was by cluster, we used the cluster as the unit of analysis. Hospital admissions of interest occurred between 1 September 2005 and 31 August 2006 ("pre-intervention period") and between 1 September 2007 and 31 August 2008 ("post-intervention period"). We then calculated rates as the ratio of the cumulative number of study residents' hospital admissions over the population size of the community. To identify the contribution of multiple admissions for individual people, we also calculated rates by using the number of unique people admitted per period. The primary outcome at the admission level allowed for multiple hospital admis sions, whereas the patient level analyses included the first admissions only. These analyses allowed estimation of the effect of CHAP on the secondary, patient level outcomes. The population denominator was the number of community dwelling people aged 65 years and over who were alive and residing in each study community on the first day of the pre-intervention 
Table 2 |Comparison of mean hospital admission rates per 1000 by study arm

\begin{tabular}{|c|c|c|c|c|c|}
\hline \multirow[b]{2}{*}{ Hospital admissions } & \multicolumn{2}{|c|}{$\begin{array}{l}\text { Pre-intervention rate (1 September } \\
2005 \text { to } 31 \text { August 2006) }\end{array}$} & \multicolumn{2}{|c|}{$\begin{array}{l}\text { Post-intervention rate (1 September } \\
2007 \text { to } 31 \text { August 2008) }\end{array}$} & \multirow[b]{2}{*}{$\begin{array}{c}\text { Rate ratio } \\
(95 \% \mathrm{Cl}) ; \mathrm{P} \text { value }\end{array}$} \\
\hline & $\begin{array}{c}\text { CHAP } \\
(n=67874)\end{array}$ & $\begin{array}{c}\text { Control } \\
(n=72768)\end{array}$ & $\begin{array}{c}\text { CHAP } \\
(n=69942)\end{array}$ & $\begin{array}{c}\text { Control } \\
(n=75 \text { 499) }\end{array}$ & \\
\hline Composite & 30.15 & 29.36 & 27.90 & 30.13 & 0.91 (0.86 to 0.97$) ;<0.01$ \\
\hline Acute myocardial infarction & 10.24 & 10.26 & 9.54 & 10.81 & 0.87 (0.79 to 0.97$) ;<0.01$ \\
\hline Congestive heart failure & 11.19 & 11.11 & 10.51 & 12.22 & 0.90 (0.81 to 0.99$) ; 0.03$ \\
\hline Stroke & 8.71 & 7.99 & 7.86 & 7.10 & 0.99 (0.88 to 1.12$) ; 0.89$ \\
\hline
\end{tabular}

and post-intervention periods according to the Ontario registered persons database.

For each outcome, we fitted linear regression models by using the Poisson distribution and the log link function. The dependent variable was the post-intervention count (that is, number of hospital admissions during the post-intervention period), and we regressed this on the intervention indicator $(1=$ intervention community $(n=20), 0=$ control community $(n=19))$ and the pre-intervention count. We used the log of the post-intervention population size as an offset parameter. We calculated relative rates (that is, event rates for intervention communities versus control communities) and 95\% confidence intervals by exponentiating the parameter estimate of the intervention indicator. We used SAS 9.1.2 for all analyses.

\section{RESULTS}

The figure shows the trial profile. Table 1 shows key baseline characteristics for the two study arms. None of the differences between the intervention and control communities at baseline reached statistical significance at the conventional level. The mean number of residents aged 65 years and over in the 39 study communities was 3606 (SD 1992), their mean age was 74.8 (0.53) years, and $42.8 \%(1.74 \%)$ were male.

All 20 intervention communities successfully implemented CHAP. A total of 1265 three hour long sessions were held in 129/145 (89\%) pharmacies during the 10 week programme. In all, 15889 unique participants had a total of 27358 cardiovascular assessments with the assistance of 577 peer volunteers: $84.2 \%$ (13 379) of participants were 65 years of age or over. Overall, 214/341 (63\%) family physicians sent 24196 personalised invitation letters, and $338(99 \%)$ agreed to receive assessment results.

Table 2 shows the rates of hospital admission for cardiovascular disease according to trial arm and study phase, as well as the ratio of these rates calculated as the number of cumulative admissions of people aged 65 years or older per period over the community population size. In the pre-intervention (baseline) period, 2243 hospital admissions for acute myocardial infarction, stroke, or congestive heart failure (our composite primary end point) occurred among residents aged 65 years and over in control communities (mean rate 29.36 per 1000) and 2032 (30.15 per 1000) in CHAP communities. In the post-intervention period, 2318 (30.13 per 1000) hospital admissions occurred in control communities and 1915 (27.90 per 1000) in the intervention communities. After adjustment for hospital admission rates in the year before the intervention, exposure to CHAP was associated with a $9 \%$ relative reduction in our composite primary end point (rate ratio $0.91,95 \%$ confidence interval 0.86 to 0.97 ; $\mathrm{P}=0.002$ ) or 3.02 fewer annual hospital admissions for cardiovascular disease per 1000 people aged 65 years and over. We found statistically significant reductions favouring the intervention communities in hospital admissions for acute myocardial infarction (rate ratio $0.87,0.79$ to $0.97 ; \mathrm{P}=0.008)$ and congestive heart failure $(0.90,0.81$ to $0.99 ; \mathrm{P}=0.029)$ but not for stroke $(0.99,0.88$ to $1.12 ; \mathrm{P}=0.89)$ (table 2). The patterns were similar when results were expressed in terms of number of unique people admitted to hospital (table 3), although fewer outcomes reached statistical significance at conventional levels.

Table 3 shows the rates of hospital admission for cardiovascular disease, as well as the secondary outcomes rates, according to trial arm and study phase and the ratio of these rates calculated as the number of unique people aged 65 years and older per period over the community population size. Analysis of secondary outcomes showed a statistically significant difference favouring the CHAP intervention in newly prescribed antihypertensive drug treatment (rate ratio $1.10,1.02$ to $1.20 ; \mathrm{P}=0.020$ ), a trend towards lower inhospital cardiovascular mortality $(0.86,0.73$ to 1.01 ; $\mathrm{P}=0.06)$, and no difference in terms of all cause mortality $(0.98,0.92$ to $1.03 ; \mathrm{P}=0.38)$ (table 3 ).

Apart from CHAP, no important cardiovascular health promotion initiatives occurred during the study period that could account for our findings.

\section{DISCUSSION}

This study is an important step forward for community based cardiovascular health promotion programmes, showing reductions in rates of hospital admission for cardiovascular disease that were significant both statistically and from a population health perspective. The findings are encouraging given the short duration of both the CHAP intervention and the follow-up period. Furthermore, CHAP was successfully implemented in all 20 randomly selected communities, suggesting that the programme's components, tools, and processes were feasible and acceptable to diverse organisations, healthcare providers, and older adults across a range of medium sized communities.

At the root of the success of CHAP was collaboration with local stakeholders, including organisations 
Table $3 \mid$ Comparison of mean number of residents admitted to hospital per 1000 by study arm

\begin{tabular}{|c|c|c|c|c|c|}
\hline \multirow[b]{2}{*}{ Residents admitted } & \multicolumn{2}{|c|}{$\begin{array}{l}\text { Pre-intervention rate (1 September } \\
2005 \text { to } 31 \text { August 2006) }\end{array}$} & \multicolumn{2}{|c|}{$\begin{array}{c}\text { Post-intervention rate } \\
\text { (1 September } 2007 \text { to } 31 \text { August 2008) }\end{array}$} & \multirow[b]{2}{*}{$\begin{array}{l}\text { Rate ratio }(95 \% \mathrm{Cl}) \\
\qquad \mathrm{P} \text { value }\end{array}$} \\
\hline & $\begin{array}{c}\text { CHAP } \\
(n=67874)\end{array}$ & $\begin{array}{c}\text { Control } \\
(n=72768)\end{array}$ & $\begin{array}{c}\text { CHAP } \\
(n=69942)\end{array}$ & $\begin{array}{c}\text { Control } \\
(n=75499)\end{array}$ & \\
\hline Composite & 24.79 & 24.64 & 23.43 & 24.22 & 0.95 (0.89 to 1.02$) ; 0.13$ \\
\hline Acute myocardial infarction & 8.89 & 8.97 & 8.17 & 9.34 & 0.89 (0.79 to 0.99 ); 0.03 \\
\hline Congestive heart failure & 9.27 & 9.24 & 8.85 & 9.31 & 0.97 (0.87 to 1.08 ); 0.59 \\
\hline Stroke & 7.81 & 7.46 & 7.23 & 6.56 & 1.01 (0.89 to 1.15$) ; 0.87$ \\
\hline $\begin{array}{l}\text { In-hospital death from } \\
\text { cardiovascular disease }\end{array}$ & 4.35 & 4.46 & 3.88 & 4.66 & 0.86 (0.73 to 1.01$) ; 0.06$ \\
\hline All cause mortality & 35.45 & 33.13 & 33.98 & 34.55 & 0.98 (0.92 to 1.03$) ; 0.38$ \\
\hline Antihypertensive treatment started & 14.66 & 14.16 & $16.35^{\star}$ & $15.31^{*}$ & 1.10 (1.02 to 1.20$) ; 0.02$ \\
\hline
\end{tabular}

involved in social and health services, family physicians, pharmacists, community nurses, volunteers, and local policymakers. The support of CHAP sessions by family physicians helped to promote participation in the programme and timely follow-up of participants. Perhaps the greatest source of the programme's success was capitalising on and coordinating the institutional and human assets of each community. These assets ranged from in-kind contributions by the local lead organisations of facilities and materials to political influence and local connections to ensure successful implementation of CHAP. On the human assets side, the programme relied heavily on a large group of locally recruited, trained, and age matched peer volunteers and the community based organisations, pharmacists, and family physicians who embraced and supported the programme and its goals.

\section{Strengths and limitations of study}

This study successfully incorporated a randomised cluster design, used peer volunteers to deliver the intervention, had a high rate of participation, mobilised and coordinated prevention activities for cardiovascular disease of both health professionals and community organisations, and relied on population based administrative data to evaluate the intervention.

Despite its many strengths, our study has several important limitations. Firstly, given the outcome measures and approach to analysis, we cannot know which specific components of CHAP were responsible for the observed reductions in hospital admissions for cardiovascular disease. We hypothesise that several different health provider or patient mitigated mechanisms might have been at work. For example, CHAP communities saw an increase in the rate of newly prescribed antihypertensive treatment. Detection and treatment of previously undiagnosed, severe hypertension could prevent hospital admissions associated with acute myocardial infarction. Other postulated mechanisms include improved adherence to guidelines for detection and treatment of cardiovascular disease by healthcare providers, improved adherence to or starting of drug treatment or lifestyle changes by older adults in the CHAP communities, or greater coordination of cardiovascular disease prevention and health promotion efforts within communities The reduction in admission rates for acute myocardial infarction and congestive heart failure but not for stroke is somewhat puzzling but may be due to the lower incidence of stroke and the fact that these rates declined in both CHAP and intervention communities during the follow-up period. The lower statistical power associated with the lower incidence of stroke requiring hospital admission as well as inability to capture the incidence of silent strokes or strokes and transient ischaemic attacks that did not necessitate admission are additional explanations for the stroke findings.

Secondly, we showed that CHAP was feasible and effective in what we considered to be a manageable number of mid-sized Ontario communities. Our findings may not hold for larger urban centres or countries where healthcare delivery is organised differently. Although volunteerism is a major social phenomenon in North America, recruitment, training, and retention of qualified and committed volunteers can be challenging, and the use of volunteers to deliver the programme is less feasible in countries where a tradition of volunteerism is not well established. CHAP was explicitly designed to target older adults, and our approach and findings are probably not generalisable to younger people.

Thirdly, we used standard, municipal boundaries to define our study population. This may have led us to underestimate the effect of the intervention if the people who participated in CHAP resided elsewhere. Finally, our original power calculations were based on considerably higher hospital admission rates for cardiovascular disease than actually occurred during the study period. This is because in addition to a secular decline in hospital admissions for cardiovascular disease, the rates used for the original power calculations were based on a more inclusive list of diagnosis codes and less refined population estimates using 2001 data.

\section{Implications of findings}

The modest success of previous community-wide cardiovascular prevention initiatives has been attributed to many factors, including the potency, duration, 


\section{WHAT IS ALREADY KNOWN ON THIS TOPIC}

The importance of small shifts in the distribution of risk factors on the overall cardiovascular health of the population has been underscored repeatedly in the literature

However, robust evidence supporting community-wide interventions to precipitate such shifts remains sparse

Community programmes for prevention of cardiovascular disease better adapted to current circumstances need to be implemented and rigorously evaluated

\section{WHAT THIS STUDY ADDS}

A collaborative, multipronged, community based cardiovascular health promotion programme targeted at older adults reduced hospital admissions for cardiovascular disease at the population level

The intervention was delivered by peer volunteers, had a high rate of participation, and mobilised and coordinated activities of both health professionals and community organisations

Reductions in rates of hospital admission for cardiovascular disease were significant both statistically and from a population health perspective

and penetration of the interventions, secular trends in morbidity and mortality from cardiovascular disease, and methodological weaknesses. ${ }^{825}$ Most have failed to detect changes in cardiovascular risk factors or mortality that could unequivocally be attributed to the interventions. Although the importance of small shifts in the distribution of risk factors on the overall cardiovascular health of the population has been underscored repeatedly in the literature, ${ }^{2627}$ robust evidence supporting community-wide interventions to precipitate such shifts remains sparse. ${ }^{8}$

CHAP's effect size was modest, and the overall mortality was not reduced, but this is not surprising given the nature of the intervention, the one year duration of the follow-up, and how we measured the effect of the intervention. Extrapolating our results to the population aged 65 years and above in Ontario, the United Kingdom, and the United States would result in approximately 5000, 30 000, and 120000 fewer annual hospital admissions for cardiovascular disease. These estimates are on a par with the benefits of populationwide reductions in dietary salt ( $2 \mathrm{~g}$ /day reduction), tobacco use (elimination of $40 \%$ of use of or exposure to tobacco), or obesity (5\% reduction in body mass index in obese people) on the annual number of cardiovascular events. ${ }^{28}$ The reported reduction in hospital admissions is comparable to the effect of comprehensive smoke-free legislation on the incidence of acute coronary events reported in a recent meta-analysis $(0.90,95 \%$ confidence interval 0.86 to 0.94$))^{29}$

The projected increase in the prevalence and incidence of cardiovascular disease and its consequences is a worldwide phenomenon. At the same time, cardiovascular disease is highly preventable and manageable through lifestyle interventions and drug treatments. CHAP-like, population based interventions offer an avenue for further investigation of how the projected effect of cardiovascular morbidity can be reduced. Our current work focuses on how CHAP can be implemented and sustained locally in a scaled down version, as a year round programme available to every member of the community. In addition, a comprehensive cost effectiveness analysis is under way. Further research at the individual level and using a broader range of process and outcome measures is needed to help to elucidate how and in whom CHAP was most effective.

We thank all members of the participating communities: all volunteer peer health educators, family physicians, pharmacists, public health nurses, and local coordinators, as well as the local lead organisations: CHATS-Community Home Assistance to Seniors (Aurora), Leamington District Memorial Hospital (Leamington), Community Care Access Centre of Wellington-Dufferin (Orangeville), PrimaCare Family Health Team (Paris), Stratford Meals on Wheels and Neighbourly Services (Stratford), VON Middlesex/Elgin (Strathroy), VON Niagara (Thorold), Tillsonburg Community Centre (Tillsonburg), VHA Home HealthCare (Wallaceburg), VON Oxford (Woodstock), Community Care Northumberland (Port Hope), Pembroke Regional Hospital (Pembroke), Orillia Soldiers' Memorial Hospital (Orillia), Community Care City of Kawartha Lakes (Lindsay), New Horizons Seniors Centre (Kenora), VON Eastern Counties Branch (Cornwall), Bayshore Home Health (Elliot Lake), The Friends (Gravenhurst), YMCA of Collingwood (Collingwood), and The Friends (Collingwood)

Contributors: JK wrote the Initial draft of the paper. All other authors provided feedback on drafts of the paper. JK, LWC, and LD were responsible for the conception of the study and primarily responsible for the overall supervision and implementation of the trial. TK, TG, SL, MAC, and $D C$ were responsible for implementation of the programme. $L T, K T$, $B Z$, and JMP did the quantitative analyses. BF, BMcD, CAL, RG, RJS, and WH provided clinical and technical inputs to programme development and implementation. JK and JMP are the guarantors.

Funding: The study was funded in part by the Canadian Stroke Network and the Ontario Ministry of Health Promotion-Ontario Stroke System. The Canadian Stroke Network is a part of the federal government supported "Networks of Centres of Excellence," whose purpose is to mobilise and support the best stroke research talent in Canada. The Government of Ontario, Ministry of Health Promotion, provided support for the mobilisation and implementation of CHAP, including salaries of the local CHAP coordinators in each of the 20 intervention communities. This study was supported by the Institute for Clinical Evaluative Sciences (ICES), a non-profit research corporation funded by the Ontario Ministry of Health and Long-Term Care (MOHLTC). The opinions, results, and conclusions are those of the authors and are independent from the funding sources. No endorsement by ICES or the Ontario MOHLTC is intended or should be inferred.

Competing interests: All authors have completed the Unified Competing Interest form at http://www.icmje.org/coi_disclosure.pdf (available on request from the corresponding author) and declare that none of the authors has financial interests that may be relevant to the submitted work Ethical approval: The study protocol was approved by the research ethics boards at Bruyère Continuing Care in Ottawa, Sunnybrook Health Sciences Centre in Toronto, and McMaster University in Hamilton. Data Sharing: No additional data available.

1 Rodgers A, Vaughan P, Prentice T, Edejer TT-T, Evans D. The world health report 2002. WHO, 2002.

2 World Health Organization. Preventing chronic disease: a vital investment. WHO, 2005.

3 Lawes CM, Vander Hoorn S, Rodgers A, International Society of Hypertension. Global burden of blood-pressure related disease, 2001. Lancet 2008;371:1513-8.

4 Lopez AD, Mathers CD, Ezzati M, Jamison DT, Murray CJ. Global and regional burden of disease and risk factors, 2001: systematic analysis of population health data. Lancet 2006;367:1747-57.

5 Manuel DG, Lim J, Tanuseputro P, Anderson GM, Alter DA, Laupacis A, et al. Revisiting Rose: strategies for reducing coronary heart disease. BMJ 2006;332:659-62.

6 World Health Organization. Prevention of recurrent heart attacks and strokes in low and middle income populations: evidence-based recommendations for policy makers and health professionals. WHO, 2003.

7 Vasan RS, Beiser A, Seshadri S, Larson MG, Kannel WB, D’Agostino $\mathrm{RB}$, et al. Residual lifetime risk for developing hypertension in middle-aged women and men: the Framingham Heart Study. JAMA 2002;287:1003-10. 
8 Pennant M, Davenport C, Bayliss S, Greenheld W, Marshall T, Hyde C. Community programs for the prevention of cardiovascular disease: a systematic review. Am / Epidemiol 2010;172:501-16.

9 Karwalajtys T, McDonough B, Hall H, Guirguis-Younger M, Chambers LW, Kaczorowski J, et al. Development of the volunteer peer educator role in a community Cardiovascular Health Awareness Program (CHAP): a process evaluation in two communities. J Community Health 2009;34:336-45.

10 Kaczorowski J, Chambers LW, Karwalajtys T, Dolovich L, Farrell B, McDonough B, et al. Cardiovascular Health Awareness Program (CHAP): a community cluster-randomised trial among elderly Canadians. Prev Med 2008;46:537-44.

11 Chambers LW, Kaczorowski J, Dolovich L, Karwalajtys T, Hall HL, McDonough B, et al. A community-based program for cardiovascular health awareness. Can J Public Health 2005;96:294-8.

12 Jones C, Simpson SH, Mitchell D, Haggarty S, Campbell N, Then K, et al. Enhancing hypertension awareness and management in the elderly: lessons learned from the Airdrie Community Hypertension Awareness and Management Program (A-CHAMP). Can J Cardiol 2008;24:561-7.

13 Carter M, Karwalajtys T, Chambers L, Kaczorowski J, Dolovich L, Gierman T, et al. Implementing a standardized community-based cardiovascular risk assessment program in 20 Ontario communities. Health Promot Int 2009;24:325-33.

14 Thomson O'Brien MA, Oxman AD, Haynes RB, Davis DA, Freemantle N, Harvey EL. Local opinion leaders: effects on professional practice and health care outcomes. Cochrane Database Syst Rev 2000;2:CD000125.

15 Austin PC, Daly PA, Tu JV. A multicenter study of the coding accuracy of hospital discharge administrative data for patients admitted to cardiac care units in Ontario. Am HeartJ 2002;144:290-6.

16 Lee DS, Donovan L, Austin PC, Gong Y, Liu PP, Rouleau JL, et al. Comparison of coding of heart failure and comorbidities in administrative and clinical data for use in outcomes research. Med Care 2005;43:182-8.

17 Tirschwell DL, Longstreth WT Jr. Validating administrative data in stroke research. Stroke 2002;33:2465-70.

18 Humphries KH, Rankin JM, Carere RG, Buller CE, Kiely FM, Spinelli J]. Co-morbidity data in outcomes research: are clinical data derived from administrative databases a reliable alternative to chart review? J Clin Epidemiol 2000;53:343-9.

19 Tu K, Mamdani MM, Tu JV. Hypertension guidelines in elderly patients: is anybody listening? Am J Med 2002;113:52-8.

20 Kralj B. Measuring "rurality" for the purposes of health care planning an empirical measure for Ontario. Ont Med Rev 2000;67:33-52.

21 Johns Hopkins University School of Hygiene and Public Health. John Hopkins University ACG case-mix adjustment system [computer program]. Johns Hopkins University School of Hygiene and Public Health, 1997.

22 Sundararajan V, Henderson T, Perry C, Muggivan A, Quan H, Ghali WA. New ICD-10 version of the Charlson comorbidity index predicted in-hospital mortality. J Clin Epidemiol 2004;57:1288-94.

23 Hux JE, Ivis F, Flintoft V, Bica A. Diabetes in Ontario: determination of prevalence and incidence using a validated administrative data algorithm. Diabetes Care 2002;25: 512-6.

24 McCullough PA, Philbin EF, Spertus JA, Kaatz S, Sandberg KR, Weaver WD. Confirmation of a heart failure epidemic: findings from the Resource Utilization Among Congestive Heart Failure (REACH) study. J Am Coll Cardiol 2002;39:60-9.

25 Parker DR, Assaf AR. Community interventions for cardiovascular disease. Prim Care 2005;32:865-81.

26 Rose G. The strategy of preventive medicine. Oxford University Press, 1992.

27 Thompson BT, Coronado G, Snipes SA, Puschel K. Methodological advances and ongoing challenges in designing community based health promotion programs. Annu Rev Public Health 2003;24:315-40.

28 Bibbins-Domingo K, Chertow GM, Coxson PG, Moran A, Lightwood JM, Pletcher MJ, et al. Projected effect of dietary salt reductions on future cardiovascular disease. $N$ Engl J Med 2010;362:590-9.

29 Mackay DF, Irfan MO, Haw S, Pell JP. Meta-analysis of the effect of comprehensive smoke-free legislation on acute coronary events. Heart 2010;96:1525-30.

Accepted: 20 October 2010 